\title{
Isolated Myeloid Sarcoma of the Maxillary Sinus: A Case Report and Review of Literature
}

Chi-Kuang Young ${ }^{1}$, Tuan-Jen Fang ${ }^{1}$, Yushin-Hung ${ }^{2}$, Wen-Yu Chuang ${ }^{3}$ and Ta-Jen Lee ${ }^{1 *}$

${ }^{1}$ Department of Otolaryngology, Chang Gung Memorial Hospital at Linkou and Taipei, Taiwan

${ }^{2}$ Department of Hematology, Chang Gung Memorial Hospital at Linkou and Taipei, Taiwan

${ }^{3}$ Department of Pathology, Chang Gung Memorial Hospital at Linkou and Taipei, Taiwan

\begin{abstract}
Myeloid sarcoma is a rare malignant disease defined as extramedullary infiltration of immature myeloid cells and may precede or occur synchronously with acute myeloid leukemia. We reported a 35-year-old male of isolated myeloid sarcoma who presented with symptoms similar to chronic rhinosinusitis initially. Isolated myeloid sarcoma in the paranasal sinuses is exceedingly rare after reviewing the previous literatures. Through proper histological, adequate panels of immunohistochemical stain (positive markers including CD68/KP1, myeloperoxidase, CD 117, CD 99, CD68/PG-M1, lysozyme, CD34, terminal deoxynucleotidyl transferase and negative markers including CD3, CD20, CD45RO and CD79a) and cytogenic study lead to accurate diagnosis. Early intervention with systemic chemotherapy with cytarabine-based regimens is the treatment of choice. The role of chromosomal aberrations and genetic abnormality related to prognosis remain uncertain.
\end{abstract}

Keywords: Myeloid sarcoma; Sinus

\section{Introduction}

Myeloid sarcoma (MS) is a rare malignant disease defined aslocalized infiltration of immature myeloid cells occurring in extramedullary sites [1]. In 1811, the British physician Burns first described this condition and was later named as "Chloroma" by King due to the greenish color of tumors attributed to the enzyme myeloperoxidase [1,2]. The connection between leukemia and chloroma was discovered by Dock in 1904 [3]. Rappaport renamed the tumor as granulocytic sarcoma because their destructive nature developed from the immature cells of granulocytic series and the display of color other than green [4]. Myeloid sarcoma was defined as a subgroup of myeloid neoplasm and acute leukemia in the revised 2008 World Health Organization Classification and became the formal nomenclature [5]. Myeloid sarcoma occurs most commonly in in the skin, bone and lymph nodes. It has been also reported in others organs such as central nervous system, orbits, bronchus, heart, gastrointestinal tract, kidney, bladder and reproductive organs [5-7]. It is frequently occurred concomitantly in patients with acute myeloid leukemia (AML), myeloproliferative diseases or myelodysplastic syndrome (MDS) [6]. It could also be the initial manifestation of relapsing AML. In rare condition, myeloid sarcoma could be de novo occurrence and precede AML by months or years $[8,9]$. Here we report a rare case of isolated myeloid sarcoma presented initially as chronic rhinosinusitis.

\section{Case Report}

The patient was a 35-year-old male suffering from left side nasal obstruction and purulent rhinorrhea for one year. He did not have any specific underlying medical history or family history. The symptoms persisted despite regular medical treatment. Progressive left cheek numbness sensation and sense of pressure were also mentioned. Under sinuscopy examination, mucopus over bilateral nasal cavity and left nasal polyposis with complete nasal obstruction were noted. Further paranasal sinus CT scan demonstrated an expansile soft tissue mass occupying the left maxillary sinus and left nasal cavity extending to left posterior choana (Figure 1) with bilateral frontal, ethmoid and maxillary sinus mucosal thickening suggestive of chronic rhinosinusitis. Endoscopic sinus surgery was performed in January 2009 and the specimen was sent for pathologic examination.

Histologic examination of the specimen demonstrated that the

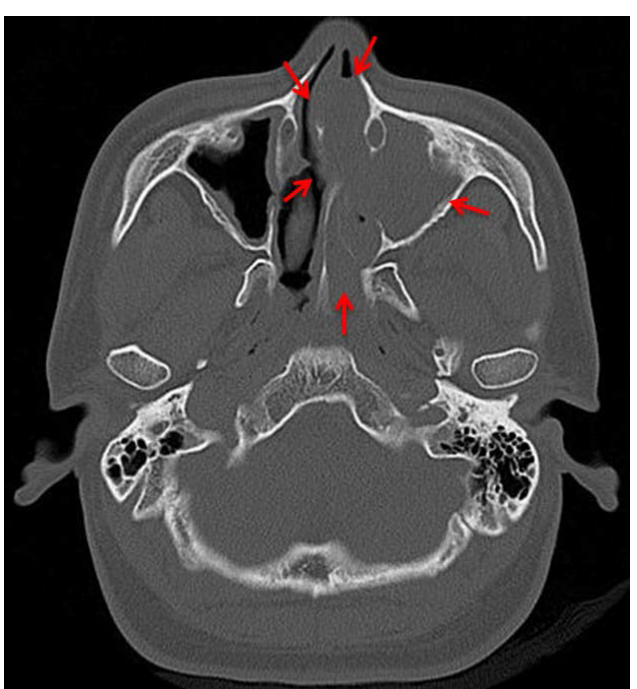

Figure 1: The coronal view of the paranasal sinus computed tomogram reveals soft tissue mass extend from left maxillary sinus to left posterior choana with sclerotic change of adjacent sinus wall (arrowhead).

*Corresponding author: Ta-Jen Lee, Department of Otolaryngology, Chang Gung Memorial Hospital at Linkou and Taipei, Taiwan, 5, Fu-Shin Street, Kweishan, Taoyuan 333, Taiwan, Tel: +886-3-3281200; Ext 8466; Fax: +886-33979361; E-mail: entlee@adm.cgmh.org.tw

Received February 24, 2014; Accepted March 26, 2014; Published March 28 2014

Citation: Young CK, Fang TJ, Yushin-Hung, Chuang WY, Lee TJ (2014) Isolated Myeloid Sarcoma of the Maxillary Sinus: A Case Report and Review of Literature. J Cytol Histol 5: 234. doi:10.4172/2157-7099.1000234

Copyright: (c) 2014 Young CK, et al. This is an open-access article distributed under the terms of the Creative Commons Attribution License, which permits unrestricted use, distribution, and reproduction in any medium, provided the original author and source are credited. 
Citation: Young CK, Fang TJ, Yushin-Hung, Chuang WY, Lee TJ (2014) Isolated Myeloid Sarcoma of the Maxillary Sinus: A Case Report and Review of Literature. J Cytol Histol 5: 234. doi:10.4172/2157-7099.1000234

paranasal sinus mucosa was surrounded by a dense infiltration of mononuclear blast-like cells (Figure 2). The cells were intermediatesized composed of prominent nucleoli and round to oval nuclei with high nuclear-to-cytoplasmic ratio. Immunohistochemical stain of the paraffin-embedded tissue sections showed that the blast cells were positive for terminal deoxynucleotidyl transferase (TdT), CD68/KP1, CD43, CD99 and CD117 (Figure 3). The myeloperoxidase (MPO), lysozyme, cyclin D1, TIA-1, CD1a and CD56 were all negative. The Band T-lineage markers including CD2, CD3, CD4, CD5, CD8, CD20, CD79a and PAX-5 were all negative. The histologic findings confirmed the diagnosis of myeloid sarcoma.

The patient's blood cell count was normal at the time of diagnosis of nasal cavity myeloid sarcoma. Bone marrow study revealed normal cellularity on 3 February, 2009, and the chromosome analysis showed a $46 \mathrm{XY}$ karyotype. The cytogenetic studies were negative for $\mathrm{t}(8 ; 21)$ AML1-ETO translocations. The patient received induction chemotherapy with Daunomycin $\left(60 \mathrm{mg} / \mathrm{m}^{2} /\right.$ day, days $\left.1-3\right)$ and cytarabine (100 mg/m²/day, days 1-7) in February, 2009 and complete remission was achieved. In February 2010, his blood count showed pancytopenia (hemoglobin $11.5 \mathrm{~g} / \mathrm{dl}$, platelet count: 20,000/ul, WBC:1800/ul, Seg:22\%, lym:71\%, blast:0\%) during routine followup. Subsequent bone marrow aspiration showed tumor infiltration

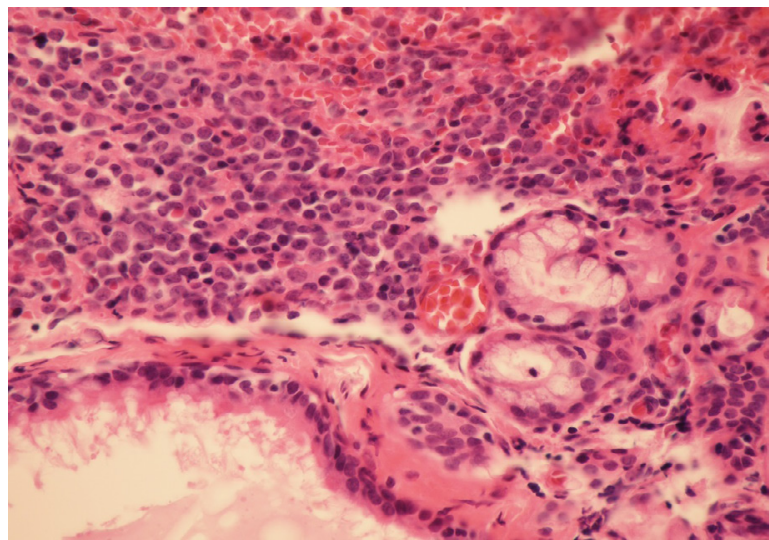

Figure 2: Histology showing sinus mucosa infiltrated by immature, intermediatesized mononuclear cells with high nuclear-to-cytoplasmic ratio and prominent nucleoli. (hematoxylin and eosin staining, X400).
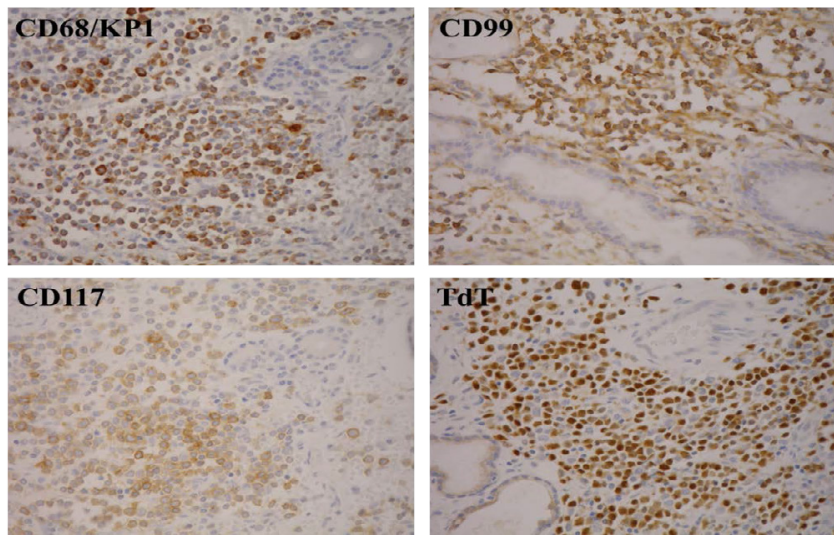

Figure 3: Immunohistochemical staining revealed that the atypical round cells were positive for CD68, CD99, CD117 and TdT. (original magnification, X400) Abbreviation: CD, cluster of differentiation; TdT, terminal deoxynucleotidyl transferase. (blast reported as 74\%). The diagnosis of AML was then made. The flow cytometry revealed positive for CD13, CD33, CD34, CD56 and CD117 and negative for CD7, CD14, CD15, CD19 and CD64. The subsequent cytogenetic studies were negative for $\mathrm{t}(8 ; 21)$ AML1-ETO translocations, CBFb-MYH11, MLL-PTD, NPM1 and FLT3 mutation. The chromosome study was $46, \mathrm{X},-\mathrm{Y},-21,+2 \operatorname{mar}[21] / 45, \mathrm{X},-\mathrm{Y},-21$, + mar[4]/46, XY[4]. The patient refused allogeneic hematopoietic stem cell transplantation. Reinduction chemotherapy with Etoposide (100 $\mathrm{mg} / \mathrm{m}^{2}$ for 2 days) and Cytarabine $\left(100 \mathrm{mg} / \mathrm{m}^{2}\right.$ for 7 days) was initiated in April 2010. He had recurrent anal fistula with severe local infection and myelosuppression during routine follow-up. He received fistuletomy in February 2011 and local therapy for the wound afterwards. Recurrent pancytopenia occurred in May 2011, with bone marrow study showing relapsed AML and CT scan revealing a recurrent nasal cavity tumor. He received salvage chemotherapy with Mitoxantrone $\left(12 \mathrm{mg} / \mathrm{m}^{2}\right.$ for 2 days), Etoposide $\left(100 \mathrm{mg} / \mathrm{m}^{2}\right.$ for 2 days $)$ and Cytarabine $\left(1 \mathrm{~g} / \mathrm{m}^{2} \mathrm{q} 12 \mathrm{~h}\right.$ QOD for 3 days). The patient expired due to severe pneumonia with myelosuppression in May 2011.

\section{Discussion}

Myeloid sarcoma is a rare clinical condition. Pileri et al. [8] in a large series of 92 patients reported that $35 \%$ of cases occurred concomitantly with AML, 38\% of cases had a previous AML history and $27 \%$ of cases presented as isolated myeloid sarcoma [9]. The lesion could be solitary or multifocal involvement. The clinical symptoms and signs varied depending on the involved anatomic area and tumor size. Isolated myeloid sarcoma in paranasal sinus is exceedingly rare. We have reviewed the literatures in English, only 6 patients with MS involvement in nasal cavity were reported (Table 1) [10-15]. Among the patients, only two cases (case 1 and case 5) were isolated MS and the others presented with AML history or synchronous MDS. The present case is the third reported isolated MS involved paranasal sinus.

The pathogenesis of myeloid sarcoma regarding to extramedullary infiltration is still under investigation. In contrast to the normal homing signals of normal leukocyte in vascular and lymphatic system, stefanidakis et al proposed a study that supramolecular complex composed of B2 integrins and MMP-9 in AML derived cell is required for pericellular proteolysis and migration [16]. Faaij et al. [17] reported that the skin myeloid sarcoma among pediatric AML patients displayed the unique chemokine receptors including CCR5, CXCR4, CXCR7 and CX3CR1 and their interaction results in homing and retention of AML blast in the skin [17].

Diagnosis of MS in a nonleukemic patient is often a challenge for clinician and pathologist. The presenting symptoms are not specific, as in our case with the initial symptoms suggestive of chronic sinusitis. Menasce et al reported that all the 14 cases without previous history of myeloproliferative diseases were incorrected diagnosed, with nonHodgkin's lymphoma the most common misdiagnosis [18]. The mainstay of diagnosis is histopathologic and cytologic confirmation. In histology examination, it must be differentiated from other small blue round cell tumor including lymphoma, neuroblastoma, rhabdomyosarcoma, Ewing's sarcoma, primitive neuroectodermal tumor, and medulloblastoma, undifferentiated carcinoma or melanoma. Further classification of MS according to the cell type and the cell maturity were granulocytic, monoblastic or myelomonocytic types and immature, mature and blastic types respectively [13]. The immunohistochemical analysis is mandatory for accurate diagnosis if the hematoxylin and eosin stain demonstrated medium to largesized pleomorphic cells with irregular nuclear outline, prominent 


\begin{tabular}{|c|c|c|c|c|c|c|}
\hline Case & Age/gender & Clinical features & Diagnosis Associated & Cytogenetics & Outcomes & Reference \\
\hline 1 & 20/female & Left maxillary and sphenoid sinus mass & Isolated MS & $t(19: 1)$ & $\begin{array}{l}\text { Chemotherapy then AHSCT; CR at } 18 \\
\text { months }\end{array}$ & Prades et al. [10] \\
\hline 2 & $72 /$ female & Right maxillary and ethmoidal sinusitis & AML (M0), 1 year earlier & Not reported & Hydroxycarbamide and surgical debridment & Ferrl et al. [11] \\
\hline 3 & $63 /$ male & Right maxillary sinusitis & Synchronous MDS & Normal & $\begin{array}{l}\text { Died of systemic infection } 2 \text { years after the } \\
\text { first symptoms }\end{array}$ & Jo et al. [12] \\
\hline 4 & $37 /$ male & Nasal cavity mass & AML(M3), 3 years earlier, & Normal & $\begin{array}{l}\text { Chemotherapy and radiotherapy } 20 \mathrm{~Gy} \text {, died } \\
35 \text { months later after MS diagnosed }\end{array}$ & Lan et al. [13] \\
\hline 5 & 56/female & Left maxillary sinus & Isolated MS & Not reported & chemotherapy; CR at 4 months & Mei et al. [14] \\
\hline 6 & 73/male & Left ethmoid sinus with & AML (M6), 1 year earlier & Normal & $\begin{array}{l}\text { Endoscopic debridement followed by } \\
\text { radiotherapy, died } 18 \text { moth after diagnosis } \\
\text { of AML }\end{array}$ & Kuo et al. [15] \\
\hline 7 & $35 /$ male & Left maxillary sinusitis & Isolated MS & Normal & $\begin{array}{l}\text { Surgical biopsy and chemotherapy, died } 28 \\
\text { months later after MS diagnosed }\end{array}$ & $\begin{array}{l}\text { Present } \\
\text { case }\end{array}$ \\
\hline
\end{tabular}

Abbreviations: AHSCT, allogeneic hematopoietic stem cell transplant; AML, acute myeloid leukemia; CR, complete remission; MS, myeloid sarcoma; MDS, myelodysplastic syndrome

Table 1: Summary of reported case of myeloid sarcoma involving nasal cavity.

nucleoli and high nuclear-to-cytoplasmic ratio. The most common expressed positive markers for myeloid sarcoma were CD68/KP1, followed by myeloperoxidase (MPO), CD 117, CD 99, CD68/PG-M1, lysozyme, CD34, terminal deoxynucleotidyl transferase (TdT), CD56, CD61, CD30, glycophorin and CD 4. For myeloid differentiation of myeloid sarcoma, CD13, CD33, CD117 and MPO were the common markers, while CD14, CD163 and CD11c were the common markers for monoblast differentiation [19]. The B- and T-lineage markers including CD3, CD20, CD45RO and CD79a should be examined to exclude aggressive lymphoma. In our case, the positive marker for TdT and CD 117 demonstrated the immaturity of hematopoietic progenitor cells. Positive markers for myeloid origin (CD68/kp1 and CD99) and negative markers for lymphoid orgin (CD3, CD20 and CD79a) confirmed the diagnosis of myeloid sarcoma.

Further bone marrow biopsy is warranted to rule out concurrent bone marrow involvement once myeloid sarcoma confirmed. Cytogenetic and fluorescence in situ hybridization (FISH) analysis should also be performed as part of diagnosis because the reported incidence of chromosomal aberrations was found in approximately $54.3 \%$ of cases [8]. A variety of chromosomal abnormalities including MLL rearrangement, $\mathrm{t}(8 ; 21)$, monosomy 7 , trisomy 8 , MLL splitting, $\operatorname{inv}(16)$, trisomy 4 , monosomy $16,16 \mathrm{q}-, 5 \mathrm{q}-, 20 \mathrm{q}-$, and trisomy 11 were found to be associated with myeloid sarcoma [8]. The rate of $t(8 ; 21)$ AML1-ETO translocations in myeloid sarcoma was controversial, which is reported $43 \%$ (17/39patients) by Dusenbery et al. [20] and around $3.3 \%$ (1/30 patients) by Pileri et al. [8,20]. Another common chromosome rearrangement "inv(16)", resulting in the fusion of CBFB and MYH11 genes, was found to present in myeloid sarcoma with intestinal involvement [21]. Nucleophosmin (NPM) 1 mutations and FMS-related tyrosine kinase 3 (FLT3) mutations, the common genetic abnormality in AML, were reported $15 \%$ of $181 \mathrm{MS}$ patients by Falini et al. [22] and 33\% of 9 MS with synchronous AML patients by Ansari-Lari et al. $[22,23]$. However, the clinical significances regarding to the prognosis or treatment effect for MS patient with above genetic abnormality remain to be discovered and compared with AML.

Myeloid sarcoma is a rare disease with poor prognosis. Meis et al. [24] revealed that $87 \%$ (13 of 15) of patients diagnosed with granulocytic sarcoma subsequently develop AML in a mean time period of 10.5 months (range from 1 to 49 months) [24]. Therefore, treatment should be arranged shortly after initial diagnosis. Systemic chemotherapy with cytarabine-based regimens, as conventional AML type, is recommended currently $[25,26]$. The role of radiotherapy was mainly on patients with isolated myeloid sarcoma or treatment failure by chemotherapy, while surgery is reserved for tissue proof or patients with acute symptoms such as nerve compression [27]. Allogeneic hematopoietic stem cell transplantation (AHSCT) is another treatment of choice but needs further prospective studies for evaluation.

In conclusion, despite the rarity of the disease and diagnostic difficulty for clinician, myeloid sarcoma could be correctly diagnosed via adequate panels of immunohistochemical stains. The bone marrow biopsy, cytogenetic study and molecular analysis are also mandatory for the synchronous AML. Systemic chemotherapy should be administrated shortly once the diagnosis confirmed. Further prospective studies are necessary for stratification the role of chromosome and genetic abnormality and the treatment outcomes.

\section{References}

1. Burns A (1811) Observations in Surgical Anatomy, Head and Neck. Edinburgh Scotland, Thomas Royce.

2. King A (1853). "A case of chloroma". Monthly J Med 17: 17

3. Dock G, Warthin AS (1904) A new case of chloroma with leukemia. Trans Assoc Am Phys. 19: 64-115.

4. Rappaport H (1966) Tumors of the hematopoietic system. Atlas of Tumor Pathology, Section III, Fascicle 8. Washington DC: Armed Forces Institute of Pathology 241-243.

5. Vardiman JW1, Thiele J, Arber DA, Brunning RD, Borowitz MJ, et al. (2009) The 2008 revision of the World Health Organization (WHO) classification of myeloid neoplasms and acute leukemia: rationale and important changes. Blood 114 937-951.

6. Neiman RS, Barcos M, Berard C, Bonner H, Mann R, et al. (1981) Granulocytic sarcoma: a clinicopathologic study of 61 biopsied cases. Cancer 48: 1426-1437.

7. Traweek ST, Arber DA, Rappaport H, Brynes RK. (1993) Extramedullary myeloid cell tumors. An immunohistochemical and morphologic study of 28 cases. Am J Surg Pathol 17: 1011-1019.

8. Pileri SA, Ascani S, Cox M, Campidelli C, Bacci F, et al. (2007) Myeloid sarcoma: clinicopathologic, phenotypic and cytogenetic analysis of 92 adult patients. Leukemia 21: 340-350.

9. Jaffe ES, Harris NL, Stein H, Vardiman JW (2001) Pathology and Genetics. Tumours of Haematopoietic and Lymphoid Tissues. Lyon: IARC Press.

10. Prades JM, Alaani A, Mosnier JF, Dumollard JM, Martin C (2002) Granulocytic sarcoma of the nasal cavity. Rhinology 40:159-161.

11. E Ferri, C Minotto, F lanniello, S Cavaleri, E Armato, et al. (2005) Maxilloethmoidal chloroma in acute myeloid leukaemia: Case report. Acta Otorhinolaryngol Ital. 25: 195-199.

12. Jo JH, Chi HS, Cho KJ (2009) Granulocytic sarcoma of the maxillary sinus. A case report. Basic and Applied Pathology 2: 72-74.

13. Lan TY, Lin DT, Tien HF, Yang RS, Chen CY, et al. (2009) Prognostic factors 
Citation: Young CK, Fang TJ, Yushin-Hung, Chuang WY, Lee TJ (2014) Isolated Myeloid Sarcoma of the Maxillary Sinus: A Case Report and Review of Literature. J Cytol Histol 5: 234. doi:10.4172/2157-7099.1000234

Page 4 of 4

of treatment outcomes in patients with granulocytic sarcoma. Acta Haematol 122: $238-246$.

14. Mei KD, Lin YS, Chang SL (2013) Myeloid sarcoma of the cheek and the maxillary sinus regions. J Chin Med Assoc. 76: 235-238.

15. Kuo CL, Yu YB, Li WY, Lee YL (2013) Unusual coexistence of sinonasal myeloid sarcoma and acute fulminant invasive fungal sinusitis: a diagnostic dilemma. The Journal of Laryngology \& Otology 127: 415-418.

16. Stefanidakis M, Karjalainen K, Jaalouk DE, Gahmberg CG, O'Brien S, et al. (2009) Role of leukemia cell invadosome in extramedullary infiltration. Blood 114: 3008-3017

17. Faaij CM, Willemze AJ, Revesz T, Balzarolo M, Tensen CP, et al. (2010) Chemokine/chemokine receptor interactions in extramedullary leukaemia of the skin in childhood AML: differential roles for CCR2, CCR5, CXCR4 and CXCR7. Pediatr Blood Cancer 55: 344348.

18. Menasce LP, Banerjee SS, Beckett E, Harris M. (1999) Extra-medullary myeloid tumour (granulocytic sarcoma) is often misdiagnosed: a study of 26 cases. Histopathology 34: 391-398.

19. Avni B1, Koren-Michowitz M (2011) Myeloid sarcoma: current approach and therapeutic options. Ther Adv Hematol 2: 309-316.

20. Dusenbery KE, Howells WB, Arthur DC, Alonzo T, Lee JW, et al. (2003) Extramedullary leukemia in children with newly diagnosed acute myeloid leukemia: a report from the Children's Cancer Group. J Pediatr Hematol Oncol 25: 760-768.

21. Tsimberidou AM, Kantarjian HM, Wen S, Keating M, O'Brien S, et al. (2008) Myeloid sarcoma is associated with superior event free survival compared with acute myeloid leukemia. Cancer 113: 1370-1378.

22. Falini B, Lenze D, Hasserjian R, Coupland S, Jaehne D, et al. (2007) Cytoplasmic mutated nucleophosmin (NPM) defines the molecular status of a significant fraction of myeloid sarcomas. Leukemia 21: 1566-1570.

23. Ansari-Lari MA, Yang CF, Tinawi-Aljundi R, Cooper L, Long P, et al. (2004) FLT3 mutations in myeloid sarcoma. Br J Haematol 126: 785-791.

24. Meis JM, Butler JJ, Osborne BM, Manning JT (1986) Granulocytic sarcoma in nonleukemic patients. Cancer 58: 2697-2709.

25. Yamauchi K, Yasuda M (2002) Comparison in treatments of nonleukemic granulocytic sarcoma: report of 2 cases and a review of 72 cases in the literature. Cancer 94: 1739-1746.

26. Wiernik PH, Banks PL, Case DC Jr (1992) Cytarabine plus idarubicin or daunorubicin as induction and consolidation therapy for previously untreated adult patients with acute myeloid leukemia. Blood. 79: 313-319.

27. Tsimberidou AM, Kantarjian HM, Estey E, Cortes JE, Verstovsek, S, et al (2003) Outcome in patients with nonleukemic granulocytic sarcoma treated with chemotherapy with or without radiotherapy. Leukemia 17: 1100-1103. 